\title{
Educators' Adversity Quotient: Rising Above Challenges in the Time of Pandemic
}

\author{
Zephora Ann Ngujo Pino ${ }^{1, \text { *, Jewish Araneta Merin }}{ }^{1,2}$ \\ ${ }^{1}$ Guidance and Research Center, St. Alphonsus Catholic School, Lapu-Lapu City, Philippines \\ ${ }^{2}$ College of Teacher Education, Cebu Normal University, Cebu City, Philippines
}

Email address:

zephorapino26@gmail.com (Z.A. N. Pino), jewishmerin@gmail.com (J. A. Merin)

${ }^{*}$ Corresponding author

To cite this article:

Zephora Ann Ngujo Pino, Jewish Araneta Merin. Educators' Adversity Quotient: Rising Above Challenges in the Time of Pandemic. Education Journal. Vol. 10, No. 4, 2021, pp. 119-125. doi: 10.11648/j.edu.20211004.12

Received: May 7, 2021; Accepted: June 1, 2021; Published: July 6, 2021

\begin{abstract}
Being one of the greatly affected sectors in this global crisis, educators hold multiple challenges on top of their responsibilities. Their ability to surmount these adversities and unprecedented challenges - defined as Adversity Quotient, play a vital role especially in this time of pandemic. This study aimed to determine the adversity quotient (AQ) of the educators through descriptive methodology. The control, ownership, reach and endurance (CORE) are the dimensions that measured the level of AQ. Data were collected using the Adversity Response Profile (ARP) questionnaire that measures an individual's ability to respond when confronted with challenges or adversities, and interview guide questions that determine the perceived challenges. The results revealed that in general, educators have moderate AQ. Moreover, there are two perceived challenges that the educators encountered: distance learning and dealing with the stakeholders. Thus, these challenges made the educators more vulnerable in the time of pandemic. Although educators learn how to bear up against difficulties, it is still imperative to know and address one's adversity quotient. A webinar on Understanding One's AQ: Accepting Challenges and Rising above it, is relevant and deemed helpful in addressing the needs of the educators.
\end{abstract}

Keywords: Adversity Quotient, Educators, Challenges, Adversities, Pandemic

\section{Introduction}

One inevitable fact about life is that it is a constant struggle. People from all walks of life are bound to encounter limitless challenges - may it come in extreme forms or just in trivial ones. Adversity will always be a part of life that one must have to deal with. In recent times, the world has faced a greater adversity. People all over the globe never expected the whole world to stop due to a pandemic caused by the novel coronavirus (COVID-19). No one has ever prepared for the crisis since it came without warning, filling most days with confusion, chaos, and worry.

The COVID-19 pandemic is not just a global threat, but it also generates a devastating impact across all sectors, including the field of education. In the Philippine setting, many schools have decided to close down their doors due to financial setbacks caused by the pandemic. This resulted in massive unemployment among educators and academe workers. Aside from that, the terrible toll that the outbreak is having on educator's lives is concretely evident as the new normal poses more worries to this sector. The Department of Education (DepEd) implemented the distance learning approach to make sure that learning remains unhampered as the country battles the pandemic [8]. However, this sudden shift of a distance learning delivery mode from the traditional face-to-face becomes a greater adversity among educators since their preparedness for it is in question.

With the nature of work that the educators have to deal with in the midst of a pandemic, it is significant to take into account their adversity quotient (AQ). Failure to deal with adversities can be a hindrance in achieving educational goals. Defined by Stoltz [16], Adversity Quotient (AQ) is a measure of how an individual responds to adversity. It consists of four dimensions - Control, Ownership, Reach and Endurance 
(CORE). People who apply AQ in their lives can still function productively despite difficulties, challenges- small or big- that confront them every day.

In this regard, the researcher is challenged to determine the Adversity Quotient (AQ) profile and their perceived challenges among educators of St. Alphonsus Catholic School (Lapu-Lapu City, Cebu) Inc. and propose a relevant program to address the well-being of the school's frontlines in this crucial time of pandemic. In general, this study aims to know how the modern-day educators rise above challenges.

\section{Theoretical Background}

Human beings are diverse. By diversity, people go through different stages of life and deal with predicaments differently. Despite exposures to stressful situations, some people can withstand, overcome, and be strengthened by these adversities. This can be explained by the Adversity Quotient Theory authored by Dr. Paul G. Stoltz. Adversity Quotient (AQ) refers to how well an individual can withstand adversity as well as his/her ability to surmount it.
Stoltz's theory is mainly composed of the CORE model, which represents the dimensions that describe the pattern of response to adversity that includes control, ownership, reach and endurance. Control measures the extent to how much an individual perceives he/she can influence an adverse event. It is a measure of resilience and the ability to turn adversity into opportunity. Ownership refers to an individual's accountability and responsibility to take actions and learn from the outcomes of an event. It contends the likelihood of a person to do something in order to improve a situation. Reach pertains to how much a certain event perceived by a person affects other areas of life. It is a measure of an individual's preparedness upon dealing with adversity. Lastly, endurance is an individual's perception of time on how long the adversity and its causes will last.

In general, Stoltz's theory revolves around the concept of "The Great Ascent" in which achieving success is likened to one's journey in climbing a mountain. In this regard, Dr. Stoltz [17] holds that achievement can be reached when one choose to move forward and progress in his/her lifelong mission, despite all obstacles or other forms of adversity.

\section{Conceptual Framework}

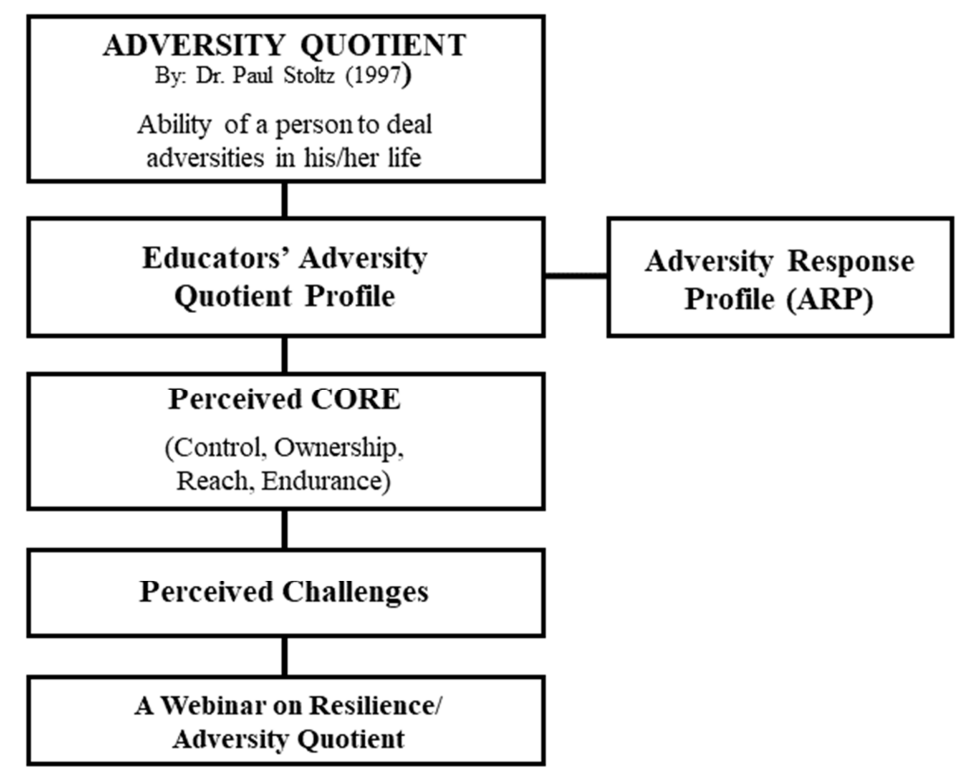

Figure 1. Conceptual Framework of the Study.

\section{Statement of the Problem}

The research study primarily aims to determine the Adversity Quotient (AQ) of Grade School Educators so as to answer the following questions:

1. What is the Adversity Quotient (AQ) level of educators?
a. High
b. Moderately High
c. Moderate
d. Moderately Low
e. Low

2. What are the perceived CORE and challenges of the educators in this time of pandemic?

3. What recommendations can be made based on the findings of the study?

\section{Review of Related Literature / Studies}

Over the years, challenges and hardships have been considered as part of life. One is bound to encounter at least multiple humps and bumps along the way. The COVID-19 pandemic has become the world's major adversity in the $21 \mathrm{st}$ 
century, in which the crisis severely affected everyone's way of life. In an already competitive society, people continue to wrestle with life in order to survive. According to Dr. Stoltz [16], every rational being has a human core drive to ascend. Hence, it is considered to be a part of an individual's common character [6]. Just like climbing a mountain, one bears the goal to reach the peak in order to achieve self-actualization. However, the ascent to the top requires diligence, endurance and persistence since barriers are inevitable along the way.

By general definition, Adversity Quotient (AQ) is a measure of one's ability to deal and respond to adversities. A person who can persevere in challenging times can achieve his/her goals in life easily [10]. There are people who can handle pressure with grace despite seemingly insurmountable odds. These people who can combat against storms in life and can turn every challenge into an opportunity are called "climbers". In congruence with his theory on the great ascent, Stoltz classified three types of people that one can possibly encounter along the journey to the peak. These are the Quitters, Campers and Climbers. Quitters refer to those people who easily quit in times of adversity. Campers rise above quitters as this group takes the challenge to climb but has the tendency to settle down on a plateau when times get rough. Lastly, climbers are the ones who embrace every challenge encountered along the way and reach the peak. The quitters, campers and climbers have different responses to the journey, thus, each of them experiences different levels of success in their lives.

The description of adversity does not only limit to minor day-to-day inconvenience, but may also come in different spheres. Canivel [4] contends that there are three levels of adversity - societal adversity, workplace adversity and individual adversity. Challenges were evident among the economic sector in this difficult time, leaving most workers struggling with a major rife for survival. In the field of education, the shift to a new learning pedagogy caused so much distress among educators. Demands are increasing as teachers are faced with constant change that calls to upgrade knowledge and skills. Nonetheless, teachers respond to these challenges differently since they have varying degrees of Adversity Quotient (AQ) [9]. Stoltz's theory can be beneficial in the effectiveness of organizations and communications. AQ will strengthen one's effectiveness in the workplace [4].

Multiple studies chronicled about Adversity Quotient (AQ) and its significance to educators in the COVID-19 outbreak. When the first few cases of COVID-19 was detected within the country, fast track adoption of digital transformation led to unprecedented changes like work from home and widespread use of online learning applications [11]. In this regard, it is relevant to understand how the prime facilitators of education are able to adjust to this abrupt transition, and what challenges they encountered while adapting to it. In the study of Alea, Fabrea, Roldan \& Faroogi [1], educators expressed their readiness to shift to distance learning education, however, lack of resources, facilities, and sufficient training to distance learning education caused them distress. Stressful situations pertaining to demands of the new normal elicit varied responses among educators due to different degrees of adversity quotient (AQ) [9].

Shen [14] claims that AQ can be used to understand employees' ability to withstand difficult work conditions and fulfill their potential. Since educators are pressured to cope with the trends in distance learning, their AQ could be a potent tool to identify their effectiveness. Research suggests that the ability of a person to deal with crucial situations at work influence one's work and performance [7]. This further contends that if one can cope up with such adversity then surely he/she can perform well in his or her work. In addition, the study of Verma, Aggarwa \& Bansal [21] stated that people with high AQ are considered more effective and efficient when considering high work performance. Consequently, the study of Solfema [15] yields that there is a relationship between the level of adversity intelligence and tutor's performance. The findings of the Solfema's [15] study bears seemingly similar results with the study of Rahmayanti, Egantara and Ramadhan [12] in which AQ has an influence on performance of honorary teachers. Thus, adversity quotient offers positive influence on work related performance [3].

\section{Research Methodology}

The study utilized Descriptive Design. It aims to determine the educators' Adversity Quotient (AQ) as well as its perceived causal factors. The educators' perception on the possible factors that affect their AQ level are gathered through Focus Group Discussion (FGD). More importantly, this study generates recommendations and intervention programs based on its findings. The respondents of the study are the Grade School Educators, for the school year 2020-2021, there is a population of forty (40) esteemed educators in the said department. An individual's Adversity Quotient (AQ) level can be measured by taking the Adversity Response Profile (ARP), a questionnaire developed by Stoltz that purports to measure an individual's ability to respond when confronted with challenges or adversities. The higher an individual's AQ score is, the higher his or her ability to persevere in the face of adversity. The ARP is a self-rating questionnaire, which comprises fourteen to-be-imagined scenarios. Each of which are followed by four different questions thought to represent the dimensions known as CORE: Core, Ownership, Reach and Endurance. The four questions are scored on a five-point bipolar scale.

\section{Research Procedure \& Data Analyses}

The researcher permission from the school directress to conduct a research study among its Grade School educators through transmittal letter. Then the researcher scheduled the administration of the test in accordance with the educators' availability. The consent forms bearing the assurance of confidentiality and agreement into being participants of the study were given to the respondents prior to the test taking proper. After answering all queries and clarifications pertaining to the study, the Adversity Response Profile (ARP) test was then administered to the respondents. Answered sheets were collected and checked after test administration. Raw scores of AQ were converted to standard scores. The researcher looked into the four dimensions of AQ (Control, Ownership, Reach, \& 
Endurance) based on the results and test interpretation. The researcher further gathered information about their perceived CORE and challenges encountered as educators in this time of pandemic through Focus Group Discussions (FGD). Three focus group discussions were conducted since educators with high, moderate and low AQ were grouped accordingly. Undertaken with consent, the educators' responses were recorded and transcribed for data presentation.

\section{Presentation, Analysis and Interpretation}

Table 1. The Educators' Adversity Quotient Descriptive Interpretation.

\begin{tabular}{llll}
\hline Descriptive Interpretation & Range of AQ & Number of Educators & Percentage \\
\hline High & $178-200$ & 1 & 3 \\
Moderately High & $161-177$ & 4 & 11 \\
Moderate & $135-160$ & 20 & 57 \\
Moderately Low & $118-134$ & 4 & 11 \\
Low & 117 and below & 6 & 17 \\
\hline
\end{tabular}

The respondents' adversity scores fall in the moderate range which implies that the majority of the educators are classified to be campers. People with moderate AQ are willing to surmount barriers but are not persistent in their efforts. These educators may sometimes prefer comfort over rough achievements and mostly shy away from negative experiences. One educator said, "With the overwhelming tasks we are experiencing in this new normal, I honestly feel demotivated at times and mostly crammed my outputs." This suggests that educators may at times become demoralized or overwhelmed especially with the demands brought by the pandemic but still, have the innate drive to deal with these challenges. High AQ characteristics have the energy and perseverance to bounce back from pitfalls. Educators belonging in this range demonstrate strong accountability for dealing with setbacks and know how to face challenges in work without allowing adversities to seep through in their lives. According to an educator with a high AQ score, "I take criticisms positively and I believe it can help me build to become a better teacher to my pupils." As also investigated by the researcher, the common ground among educators with moderately high to high AQ is their years of experience in the profession. This claim can be supported by the study of Bautista [2] which concocted that educators who were classified according to their age and academic ranks had a high adversity quotient. Educators with high $\mathrm{AQ}$ are deemed as the standard-bearers in the teaching profession since they are goal-driven despite inevitable challenges.

According to Stoltz $[16,4]$, people with low AQ tend to also have low levels of motivation, energy, performance and persistence. Respondents that have low AQ scores implies that the educators belong to moderately low to low range of carrying into action. As stated by an educator whose score falls in this range, "The list of things we do - from making modules, navigating LMS and answering endless consultations from parents to pupils may cause me so much stress that I oftentimes think that I am an ineffective teacher." Other educators also contend that criticisms they get from parents and administrators can affect them personally.

\subsection{Educators' Adversity Quotient and Its CORE Dimensions}

Knowing the educators' descriptive interpretation of their
AQ is already a good measure, however, it is deemed best to find out its dimensions as well. In this regard, the researcher computed the mean and the standard deviation (SD) from the raw data of the educators' adversity quotient and its four dimensions of control, ownership, reach, and endurance. Table 2 presents the educators' adversity quotient (AQ) and its CORE dimensions.

Table 2. Educators'Adversity Quotient with its CORE Dimensions.

\begin{tabular}{lll}
\hline Descriptive Statistics & Mean & SD \\
\hline Control & 18.571 & 2.370 \\
Ownership & 17.314 & 2.659 \\
Reach & 17.029 & 3.813 \\
Endurance & 17 & 3.749 \\
Overall AQ & 140.457 & 19.177 \\
Qualitative Description & Moderate & Moderate \\
\hline
\end{tabular}

Results show that the educators' adversity quotient yielded a computed mean score within the moderate range of the AQ descriptive interpretation. The scores implied an average capacity to deal with work demands, challenges, and difficulties [17]. The four dimensions of AQ is represented by an acronym of CORE. $\mathrm{C}$ stands for Control which pertains to the degree of influence one has over an adverse event. The educators' overall result of the Control dimension includes the highest mean score. When asked about their perceived control on challenging tasks such as module-making, conducting synchronous sessions, and dealing with work and personal conflict, educators responded through an interview that, "Tasks may be overwhelming but it's part of a teacher's job so there is no other choice but to accomplish it." Another educator said, "Although there are situations that we can't control such as other people's opinion of us, we strive hard to achieve our goals otherwise we are obliged to deal with the consequences."

The Ownership dimension of the respondents indicates that educators hold a moderate level in this dimension. This implies that most educators feel responsible for improving difficult situations encountered at work. An educator who gets high ratings in this dimension said, "I usually own up my mistakes and avoid pointing fingers. I believe there is always a next time." People with high levels of ownership accept their flaws, learn from experience and take note of it for future reference [13]. On the other hand, people who fall low in this 
dimension are those who do not hold themselves accountable for improving a situation. They have the tendency to disown their mistakes regardless of the cause [19].

$\mathrm{R}$ stands for Reach which accounts for how far a person will let adversity reach into other areas of his/her life. Respondents in this dimension still fall within the moderate range which implies that educators are equipped to deal with challenges, however, it comes with limitations. As gathered from the interview, educators who scored low in the Reach dimension agree that "criticisms may affect one's motivation to work." An educator added, "Dealing with criticisms/complaints from parents and getting handled unfairly by the administrators may cause me emotional distress that would be so hard to forget." It is common for human beings to have emotional limits [5] which explains why some educators get easily affected by negative experiences. However, some educators respond to challenges differently and find these adversities manageable that do not affect much of their life. One respondent contends, “As long as I am able to explain my side, I don't see any point to keep myself bothered about it." According to them, adversities like criticisms can be resolved through open communication.

Lastly, Endurance measures how long an adversity lasts. Respondents obtained a mean score are classified under the moderate range. A person with high endurance would perceive every difficulty encountered as short-lived, while those who possess low endurance may see an adversity as a lifetime issue [18]. Educators who possess the ability to see past adversities and continue to go through life are most likely the ones who scored high in this dimension. A tenured educator who scored high on endurance dimension said, "Problems encountered here in the workplace are just passing issues." Similarly, another educator added, "Deadlines, modules and a whole lot more - oh they're just gonna pass! I can get scolded and still wake up to try again the next day." Basically, resilient educators show no signs of being affected by life's difficulties for a long time. However, an educator who has a low AQ score contended that there are stressful instances that are just so hard to get over with and may often take a longer while to heal. In this regard, it would be best to imply that educational systems must take AQ as a critical factor because the students can benefit more from resilient and elevated educators [9].

\subsection{Perceived Challenges Encountered by Educators in the Time of Pandemic}

In addition to the results obtained from the Adversity Response Profile (ARP), it has also been observed by the researcher that the present-day educators have encountered different sets of challenges as compared to the former years. This section presents the educators' attitudes and perceptions when faced with adversity in the new normal. The succeeding discussions are about the educators' overwhelming challenges that were analyzed and transcribed to different themes.

A. Challenges of Distance Learning

From the traditional face-to-face classes, the COVID-19 outbreak has pushed educators and students to conduct alternative learning to mitigate school cancellation of classes.
However, the shift to distance learning bears its fair share of challenges among the educators. When asked about the challenges encountered, these are the following responses the educators divulged:

"Having to prepare two learning tools for offline and online learners is the reason why our job is twice as taxing."

"Maybe the most challenging part is the fact that we were not equipped with knowledge and skills required in delivering distance learning education. We were only given a limited time to prepare."

"Navigating the LMS and teaching our pupils how to use it is also a challenge."

"It's hard to monitor my pupils virtually especially in accomplishing my asynchronous activities."

"Giving instruction and responding to queries through email and messages"

In general, educators disclosed that their perceived challenges in this difficult time includes awareness and preparedness of the distance learning approach, problems on establishing communication with pupils and parents, mastery of the LMS (Aralinks), and taxing responsibilities that would often overlap with their personal time. Moreover, elderly educators added that the use of phones, laptops, tablets or any devices for distance learning is also a perceived challenge. The group who scored high and moderate on AQ contended that distance learning posits many challenges on their end but it motivates them to improve in the future. As stated by Stoltz, climbers embrace challenges and they live with a sense of urgency. They are self-motivated, highly driven and strive to get the utmost out of life. Above all, climbers are catalysts for action; they tend to make things happen.

B. Challenges Encountered with Stakeholders

Aside from the difficulties that were carried out by the distance learning education, the researcher was also able to find out that the challenges encountered by the educators are not only limited to that issue. Educators raised that their interpersonal relations with the stakeholders play a crucial role in their ability to counter adverse events. The following are some of their verbatim responses:

"I think the administrators' decision-making skill is very crucial especially in the new normal when we are expected to understand the needs of each other."

"Inconsistency in the implementation of policies caused so much distress to us teachers."

"Our efforts in preparing were oftentimes overlooked and it personally demotivates me."

"The fact that we have to deal with parents who don't respect personal boundaries"

"Some parents would want their child to be spoon-fed. It's hard to achieve my teaching goals when they keep on complaining and demanding us to do all the work by ourselves."

"It's true. Pupils are clever enough to miss synchronous sessions whenever they like."

It is evident that educators struggled in dealing with the stakeholders such as the administrators, parents and the pupils. 
Criticisms, lack of support and complaints they get from any of these stakeholders usually affects their self-esteem and motivation. Parvathy \& Praseeda [10] claims that self-esteem is linked with adversity quotient. Educators' who possess low levels of self-esteem may be less resilient as compared to those educators who feel moralized and confident with their work.

\section{Findings, Conclusions and Recommendations}

After an in-depth analysis and interpretation of data, the following findings are hereby surmised:

1. The results reveal moderate scores in the educators' over-all AQ. Specifically, the educators have also yielded moderate scores in the four dimensions of AQ namely Core, Ownership, Endurance and Reach. This implies that the AQ level of the educators of the research environment is not generally far behind the standards provided by the theory of Dr. Stoltz.

2. The challenges encountered among the educators are categorized into two - challenges of distance learning and challenges with the stakeholders. Educators divulged that their challenges of distance learning include unpreparedness of the new learning set-up, problems in monitoring pupils, mastery of the LMS, and taxing responsibilities that would often overlap with personal time. On the other hand, the respondents disclosed that the major challenges they encountered with the stakeholders are basically lack of support and consideration in their field of work.

3. A webinar on "Understanding One's AQ: Accepting Challenges and Rising above it" is a relevant proposal of the study that is deemed helpful in addressing the needs of the educators. In addition, supplementary and voluntary counseling sessions will be offered by the school's guidance office to further support the aim of the study.

\subsection{Conclusion}

Educators' Adversity Quotient (AQ) were found to be moderate which implies that amidst global and unprecedented challenges, teachers can still function and expand their potentials at work. Moreover, the differing levels of the dimensions of their adversity quotient suggest that although educators learn how to withstand difficulties, they respond to these challenges differently. Based on the educators' gathered perception, being a teacher in this crucial time means that they are bound to encounter inevitable challenges such as struggling with the abrupt shift to distance learning and dealing with their interpersonal relationship with the stakeholders. In a collective insight, pandemic has made the educators more vulnerable to challenges, which supports the importance of adversity quotient in one's life.

\subsection{Recommendations}

Recognizing the findings and conclusion of the study, the following may be recommended.

1. Emphasize the role of educators' adversity quotient in being able to improve specific skills especially in control, ownership, reach and endurance dimensions.

2. Challenges of the educators will be addressed immediately with the help and guidance of the administrators through carrying out programs tailored for this population in this time of crisis.

3. Conduct a webinar that covers the construct of adversity quotient and its importance to one's field of work.

4. Needs not addressed through the webinar, may be supplemented by the Guidance office through offering the different guidance services including follow-up counseling sessions to the educators.

\section{Acknowledgements}

The authors would like to extend their gratitude to all the people who made this research possible especially their family, colleagues and loved ones.

\section{References}

[1] Alea, L. A., Fabrea, M. F. Roldan, R. D. \& Farooqi, A. Z. (2020). Teachers' Covid-19 Awareness, Distance Learning Education Experiences and Perceptions towards Institutional Readiness and Challenges. International Journal of Learning, Teaching and Educational Research Vol. 19, No. 6, pp. 127-144. Retrieved from: https://doi.org/10.26803/ijlter.19.6.8J.

[2] Bautista, R. L., Pascua, M. G., Tiu, J., Vela, C. D. (2016). Adversity Quotient and Leadership Styles among Student Leaders in Bulacan State University. Retrieved from: https://www.peaklearning.com/wp-content/uploads/2019/05/P EAK_GRI_Bautista_Pascua_Tiu_Vela.pdf

[3] Billger, S. (2007). Principals as agents: Investigating accountability in the compensation and performance of school principals. Industrial Labor Relation Review, 61 (1), 90-107.

[4] Canivel, L. D. (2010). Principals' adversity quotient: Styles, performance and practices. Unpublished Master's Thesis, University of the Philippines, Quezon City, the Philippines. Retrieved from http://www.peaklearning.com/documents /PEAK_GRI_canivel.pdf

[5] Kirman, A., Livet, P., \& Teschl, M. (2010). Rationality and emotions. Philosophical transactions of the Royal Society of London. Series B, Biological sciences, 365 (1538), 215-219. https://doi.org/10.1098/rstb.2009.0194

[6] Korn, A. (2014). To bend, but not to break. Retrieved from https://aura.antioch.edu/cgi/viewcontent.cgi?article $=1176 \&$ co ntext=etds

[7] Lazaro, A. R. C. (2004). Adversity quotient and the performance level of selected middle managers of the different departments of the city of Manila as revealed by the 360-degree feedback system. Presentation paper in the Special Session: Workshop for Prospective Scholars, International Industrial Relations Association (IIRA), 5th Asian Regional Congress, Seoul, Korea. 
[8] Magsambol, B. (2020, June 1). FAST FACTS: DepEd's distance learning. Rappler. https://www.rappler.com/newsbreak/iq/things-to-know-depart ment-education-distance-learning

[9] Marashi, H., \& Fotoohi, M. (2017). The Relationship between Extrovert and Introvert EFL Teachers' Adversity Quotient and Professional Development. Journal of Applied Linguistics and Language Research Volume 4, Issue 3, 2017, pp. 156-170.

[10] Connors, Parvathy, U., \& Praseeda, M. (2014). Relationship between Adversity Quotient and Academic Problems among Student Teachers. IOSR Journal of Humanities and Social Science (IOSR-JHSS) Volume 19, Issue 11, Ver. VII (Nov. 2014), PP 23-26. Retrieved from: www.iosjournals.org

[11] Quimba, F. M. A., Dumaua-Cabauatan, M., Calizo, S. C., \& Pacio, L. C. (2018). E-Education in the Philippines: The Case of Technical Education and Skills Development Authority Online Program. Discussion Papers No. 2018-08, 1-45.

[12] Rahmayanti, R., Egantara, R. M. A., Ramadhan, I. (2020). The Influence of Adversity Quotient on the Performance of Honorary Teachers in City of West Bandung through Motivation as Intervening Variables. Solid State Technology Vol. 63 No. 5. Retrieved from:

https://solidstatetechnology.us/index.php/JSST/article/view/3138

[13] Sanchez, R. R. (2018). Relationship between the Adversity Quotient and Psychological Well-being of Psychology Students of Pamantasan ng Lungsod ng Maynila. Retrieved from: https://www.peaklearning.com/wp-content/uploads/2019/05/PEA K_GRI_Sanchez_October-2018.pdf.

[14] Shen, J., Wegenke, G. L., \& Cooley, V. E. (2003). Has the public teaching force become more diversified: National and longitudinal perspectives on gender, race, and ethnicity.

[15] Solfema (2017). Adversity Intelligence as a Contributing Factor of Tutor's Performance. European Journal of Education Studies. Volume 3, Issue 11. ISSN: $2501-1111$.

[16] Stoltz, P. G. (2000). Adversity quotient at work; make everyday challenges the key to your success _ Putting the principles of AQ into action. New York: Morrow.

[17] Stoltz,. P. G. (1997). Adversity quotient, turning obstacles into opportunities. New York: Wiley. ISBN: 978-0-471-17892-7.

[18] Thi, E. L. (2007). Adversity Quotient in Predicting Job Performance Viewed through the Perspective of the Big Five. Psykologiske Institutt, University of Oslo. Retrieved from: http://urn.nb.no/URN:NBN:no-17573
[19] Uplane, Megha. (2013). Adversity Quotient and Defense Mechanism of Secondary School Students. The Southern journal of educational research. 1. 303-308. 10.13189/ujer.2013.010405.

[20] Ventayin, R. J. (2018). Teachers' Readiness in Online Teaching Environment: A Case of Department of Education Teachers. Journal of Education, Management and Social Sciences, 2 (1). Retrieved from www.psurj.org/jemss

[21] Verma, S., Aggarwal, A., \& Bansal, H. (2017). The Relationship between Emotional Intelligence (EQ) and Adversity Quotient (AQ). IOSR Journal of Business and Management, 19, 49-53.

\section{Biography}

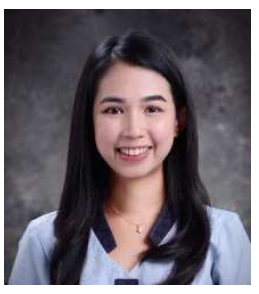

Zephora Ann Ngujo Pino, is a Guidance Associate in St. Alphonsus Catholic School (Lapu-Lapu City, Cebu) Inc., specifically handling the Grade School Department. Formerly, she had teaching experience at Asian Learning Center (2017-2018) and worked as the Guidance designate in the said school. She finished her Bachelor's Degree at Cebu Doctors' University in which her research paper got nominated for best thesis. Last 2016, she passed the Board of Licensure Examination for Psychometrician/Psychologist (BLEPP) gaining her the RPm title. She is an aspiring researcher and hopes to further her educational development by pursuing graduate studies in Cebu Normal University.

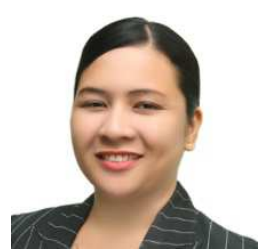

Jewish Araneta Merin, is an Associate Professor V and the Quality Assurance Officer/Lead Auditor of the College of Teacher Education at Cebu Normal University. She raised her ranks from Teacher I to Teacher III of the Department of Education Region 8, Division of Leyte, Matag-ob District (2002-2007) and continuously serving her Alma Mater at Cebu Normal University. She was one of the Deped. Regional trainees in the National English Proficiency Program (2006); served as resource person of the Region 7 - K to 12 Basic Education Curriculum in Science (2013) and DOST Project STAR (2017-2019). 